\title{
Radiological survey of past and present vermiculite miners exposed to tremolite
}

\author{
JC McDONALD, P SEBASTIEN, AND B ARMSTRONG \\ From the School of Occupational Health, McGill University, Montreal, Quebec, Canada
}

ABSTRACT Chest radiographs taken by a standard technique were obtained from 173 current employees (164 men, 9 women) of a vermiculite mine in Montana, from 80 of 110 past employees resident within 200 miles, and from 47 men from the same area without known exposure to dust. In 43 of the 80 and 24 of the 47 an earlier chest $x$ ray film was retrieved from the hospital archives. All 367 films were assessed blind and independently by three experienced readers using the ILO 1980 classification. Median radiographic assessment scores were analysed in relation to estimated cumulative exposure to the amphibole fibres that contaminate the vermiculite. Logistic regression analyses showed independent effects of age, smoking, and exposure on the prevalence of small opacities and of age and probably of exposure on pleural thickening. Overall, the data suggest that by retirement age the increase in prevalence of small opacities $(\geqslant 1 / 0)$ lies between $5 \%$ and $10 \%$ per $100 \mathrm{f} / \mathrm{ml}$ years. This gradient may be somewhat steeper than for chrysotile miners and millers, but not much so.

The survey described in the present paper is one of a series of studies undertaken to assess the health effects of work in a vermiculite mine in Libby, Montana. Two complementary programmes of research were initiated by NIOSH and ourselves, primarily because of contamination of the ore body with fibrous amphibole deposits in the tremolite series. A history and description of the mining and milling processes were given in our report on a cohort mortality study in this group of workers. ${ }^{1}$ These data showed substantial excess mortality compared with United States white men from respiratory cancers $(S M R=2 \cdot 45)$, non-malignant respiratory disease $(\mathrm{SMR}=2.55)$, and malignant mesothelioma (proportional mortality $=2 \cdot 4 \%$ ). The NIOSH mortality study of a more broadly defined cohort obtained similar results from independently assembled data. ${ }^{2}$

Vermiculite, a micaceous mineral that expands on heat treatment has many uses in construction industries, agriculture, and packaging. The largest known vermiculite deposit, at Libby, Montana, has been commercially mined since 1923 . At first it was on a small scale but, after 1939, when two companies merged, production increased: 20000 tons were shipped in 1940, 150000 in 1950, and, since 1972, about 200000 annually.

The Libby deposit is mined using the open pit

Accepted 30 September 1985 mining technique incorporating rubber tyre loaders and trucks for both ore and waste removal. Waste is discharged at the perimeter of the mined area whereas the ore is hauled to a transfer point for blending and wet beneficiation. During early years of the operation, all functions of mining and milling were performed in a dry state, leading to very dusty conditions. A series of process improvements resulted in present mine personnel operating from within enclosed air controlled cabs and a totally wet beneficiation process. Vermiculite concentrate is graded into five size fractions before shipment to expansion plants in various parts of the United States.

Fibrous tremolite has little commercial value and only one or two small mines in northern Italy produce it. On the other hand, it is a fairly common contaminant in various exploited minerals, notably some talc deposits of New York State and in the Quebec chrysotile mines where it is present in trace amounts. There has been no previously published radiological survey of tremolite miners as such but several studies of talc miners and millers exposed to varying concentrations of mineral fibre and silica. ${ }^{3}$ Pleural thickening was frequently found in these workers but parenchymal opacities much less so. These observations are not easily interpreted in terms of tremolite fibre because of the other components in the airborne dust. 
Material and methods

\section{STUDY GROUPS}

Chest radiographs were obtained from three groups. The first comprised all 164 men and nine women employed by the company on 1 July 1983 . The second was selected from 110 past male employees resident within 200 miles of the mine. This information was known as all had been traced as surviving members in the mortality cohort, the criteria for inclusion of which were employment of at least one year and date of hire before 1 January 1963. Eighty of the 110 thus identified accepted the company's invitation to come to the hospital in Libby for a chest $x$ ray film. The third group comprised 47 men without known exposure to dust who attended the hospital during the same period for a "routine" chest $x$ ray film, mostly in connection with other local employment. The latter group was not selected or matched in any way with the mine workers and was intended only to control the reading process. All 291 men (and nine women) in the three groups were examined radiologically by a standard technique, based on that outlined in appendix $A$ of the 1980 ILO guidelines. ${ }^{4}$ In 43 of the 80 ex-employees and in 24 of the 47 unexposed subjects an earlier chest $x$ ray film was located in the hospital film archives. The earlier films for the exemployees had usually been taken shortly before leaving the company and by a generally less satisfactory radiological technique. In total, 367 films were thus assembled for classification.

\section{READING PROCEDURES}

The films, with identity obliterated, were renumbered in random order and classified independently by three experienced readers. The ILO 1980 International Classification and standard sets of films were used. The readers were told only that the films were mainly from mineworkers with varying exposure to mixed dusts and that about $20 \%$ of the series were unexposed subjects. Preliminary tabulations after the readings were completed showed that, overall, $56 \%$ of the recent films were considered of good quality, $36 \%$ fair, $7 \%$ poor, and $0.4 \%$ unreadable. The corresponding ratings for the older films were $22 \%, 53 \%$, $23 \%$, and $2 \%$. Although the readers were experienced and had often worked together, interobserver variation remained. Agreement between all three readers on the presence or absence of changes was achieved in about $90 \%$ of readings for pleural calcification, costophrenic angle obliteration, and pleural thickening on the diaphragm. The rate fell to about $80 \%$ for small parenchymal opacities and for pleural plaques or diffuse thickening.

\section{EXPOSURE ESTIMATES}

Work histories were used to obtain the dates and duration of work in various locations. The mean airborne fibre concentrations for each location operation, year by year, were estimated from all available midget impinger and membrane filter measurements after a site visit and detailed review by one of us (PS). The methods of estimation and results are described fully in the mortality paper. ${ }^{1}$

\section{STATISTICAL ANALYSIS}

Radiographic readings from the three readers were combined as a median score. Two methods were used to investigate relations between $x$ ray changes and exposure to fibrous dust. Firstly, the prevalence of abnormalities was tabulated in five cumulative exposure groups, after stratification in three age groups $(20-39,40-59, \geqslant 60)$ to reduce confounding. Age standardised prevalence rates were then computed for each exposure group, the combined population being taken as standard. Secondly, logistic regression analyses for selected abnormalities were carried out in which age, smoking, and cumulative exposure were entered into the regression equation. Age was considered as a continuous variable and smoking in three groups: never smoked, ex-smokers, and current smokers. The logistic regression analysis and the fitting of linear exposure response lines to the grouped prevalences were carried out using the GLIM computer package. ${ }^{5}$

\section{Results}

The prevalence of the main radiographic changes in the current male employees and the sample of past employees, based on their most recent films, is presented in table 1. The overlap between the two groups is confined to men aged $\mathbf{4 0}$ and over. Even in these older men the rates for both parenchymal and pleural changes differ considerably but perhaps not more than might be explained by differences in mean levels of cumulative exposure. A steep age gradient in both groups is also evident, probably attributable in part to exposure. Of the 47 unexposed subjects, 32 were aged 40 or more; small opacities were read in one, pleural thickening on the chest wall in four $(8.5 \%)$, and pleural calcification in two $(2 \cdot 7 \%)$.

Table 2 gives the age standardised prevalences of small opacities and pleural thickening by cumulative exposure. Because of small numbers and, in particular, since few young men had achieved high cumulative exposures, these standardised rates are subject to rather large standard errors in the higher exposure groups. Notwithstanding these problems, the trend of increasing prevalence of small opacities with increasing exposure is unlikely to be due to chance 
Radiological survey of past and present vermiculite miners exposed to tremolite

Table 1 Percentage of radiographic changes by age

\begin{tabular}{|c|c|c|c|c|c|c|c|c|c|c|}
\hline \multirow{2}{*}{$\begin{array}{l}\text { Age } \\
\text { (years) }\end{array}$} & \multicolumn{5}{|c|}{ Current employees } & \multicolumn{5}{|c|}{ Past employees } \\
\hline & $\overline{N o}$ & $\begin{array}{l}\text { Mean } \\
\text { cumulative } \\
\text { exposure } \\
(f / m l y)\end{array}$ & $\begin{array}{l}\text { Small } \\
\text { opacities } \\
(\geqslant 1 / 0)\end{array}$ & $\begin{array}{l}\text { Pleural } \\
\text { thickening } \\
\text { (chest } \\
\text { wall) }\end{array}$ & $\begin{array}{l}\text { Pleural } \\
\text { calcification }\end{array}$ & $\overline{N o}$ & $f / m l y$ & $\begin{array}{l}\text { Small } \\
\text { opacities } \\
(\geqslant 1 / 0)\end{array}$ & $\begin{array}{l}\text { Pleural } \\
\text { thickening } \\
\text { (chest } \\
\text { wall) }\end{array}$ & Pleural \\
\hline $\begin{array}{l}20-39 \\
40-59 \\
\geqslant 60 \\
\text { All }\end{array}$ & $\begin{array}{r}80 \\
69 \\
15 \\
164\end{array}$ & $\begin{array}{r}13 \cdot 4 \\
57 \cdot 3 \\
103 \cdot 5 \\
40 \cdot 1\end{array}$ & $\begin{array}{r}2.5 \\
13 \cdot 0 \\
26 \cdot 7 \\
9 \cdot 1\end{array}$ & $\begin{array}{r}7 \cdot 5 \\
20 \cdot 3 \\
40 \cdot 0 \\
15.9\end{array}$ & $\begin{array}{l}1 \cdot 3 \\
5 \cdot 8 \\
6 \cdot 7 \\
3 \cdot 7\end{array}$ & $\begin{array}{r}1 \\
30 \\
49 \\
80\end{array}$ & $\begin{array}{r}6 \cdot 0 \\
160 \cdot 2 \\
96.1 \\
118.9\end{array}$ & $\begin{array}{l}-\overline{33 \cdot 3} \\
40 \cdot 8 \\
37 \cdot 5\end{array}$ & $\begin{array}{l}\overline{40 \cdot 0} \\
61 \cdot 2 \\
52 \cdot 5\end{array}$ & $\begin{array}{l}\overline{16 \cdot 7} \\
36 \cdot 7 \\
28 \cdot 8\end{array}$ \\
\hline
\end{tabular}

Table 2 Age standardised prevalence of abnormalities by cumulative exposure

\begin{tabular}{|c|c|c|c|c|c|c|}
\hline \multicolumn{2}{|c|}{ Cumulative exposure $(f / m l y)$} & \multirow{2}{*}{$\begin{array}{l}\text { No in } \\
\text { group }\end{array}$} & \multicolumn{2}{|c|}{ Small opacities $(\geqslant 1 / 0)$} & \multicolumn{2}{|c|}{ Pleural thickening of chest wall } \\
\hline Group & Mean & & No & Prevalence \%* & No & Prevalence \%* \\
\hline $\begin{array}{l}<10 \\
10-<20 \\
20-<100 \\
100-<200 \\
\geqslant 200\end{array}$ & $\begin{array}{r}4 \cdot 1 \\
17.5 \\
53.9 \\
144.4 \\
495.8\end{array}$ & $\begin{array}{l}92 \\
64 \\
53 \\
16 \\
19\end{array}$ & $\begin{array}{r}7 \\
12 \\
10 \\
8 \\
8\end{array}$ & $\begin{array}{l}10.6 \\
18.4 \\
15.4 \\
31.3 \\
27.9\end{array}$ & $\begin{array}{r}15 \\
14 \\
22 \\
6 \\
11\end{array}$ & $\begin{array}{l}23 \cdot 3 \\
21 \cdot 7 \\
38 \cdot 7 \\
22 \cdot 2 \\
38 \cdot 5\end{array}$ \\
\hline Total & 65.9 & 244 & 45 & $18 \cdot 4$ & 68 & $27 \cdot 9$ \\
\hline
\end{tabular}

*Directly age standardised, total study group taken as standard.

Table 3 Prevalence of abnormalities in men aged 60 or more by cumulative exposure

\begin{tabular}{|c|c|c|c|c|c|c|}
\hline \multicolumn{2}{|c|}{ Cumulative exposure $(f / m l y)$} & \multirow{2}{*}{$\begin{array}{l}\text { No in } \\
\text { group }\end{array}$} & \multicolumn{2}{|c|}{ Small opacities $(\geqslant 1 / 0)$} & \multicolumn{2}{|c|}{ Pleural thickening of chest wall } \\
\hline Group & Mean & & No & Prevalence \% & No & Prevalence \% \\
\hline $\begin{array}{l}<10 \\
10-<20 \\
20-<100 \\
100-<200 \\
\geqslant 200\end{array}$ & $\begin{array}{r}6 \cdot 5 \\
19 \cdot 0 \\
56 \cdot 7 \\
153 \cdot 4 \\
463.4\end{array}$ & $\begin{array}{r}15 \\
17 \\
16 \\
8 \\
8\end{array}$ & $\begin{array}{l}2 \\
6 \\
6 \\
6 \\
4\end{array}$ & $\begin{array}{l}13 \cdot 3 \\
35 \cdot 3 \\
37 \cdot 5 \\
75 \cdot 0 \\
50 \cdot 0\end{array}$ & $\begin{array}{r}7 \\
9 \\
10 \\
5 \\
5\end{array}$ & $\begin{array}{l}46 \cdot 7 \\
52.9 \\
62 \cdot 5 \\
62 \cdot 5 \\
62 \cdot 5\end{array}$ \\
\hline Total & 97.9 & 64 & 24 & $37 \cdot 5$ & 36 & $56 \cdot 3$ \\
\hline
\end{tabular}

Table 4 Logistic regression analysis of exposure response relations

\begin{tabular}{|c|c|c|c|c|c|}
\hline \multirow[t]{2}{*}{ Test for } & \multirow[t]{2}{*}{ In the presence of } & \multicolumn{2}{|c|}{ Small opacities $(\geqslant 1 / 0)$} & \multicolumn{2}{|c|}{ Pleural thickening of chest wall } \\
\hline & & $\overline{\chi^{2}(d f)}$ & $p$ & $\overline{\chi^{2}(d f)}$ & $p$ \\
\hline $\begin{array}{l}\text { Cumulative exposure } \\
\text { Smoking } \\
\text { Age }\end{array}$ & $\begin{array}{l}\text { Age, smoking } \\
\text { Age, cumulative exposure } \\
\text { Cumulative exposure } \\
\text { smoking }\end{array}$ & $\begin{array}{r}10 \cdot 9(1) \\
8 \cdot 2(2) \\
27 \cdot 2(1)\end{array}$ & $\begin{array}{l}\mathrm{p}<0.001 \\
\mathrm{p}<0.025 \\
\mathrm{p}<0.001\end{array}$ & $\begin{array}{r}5.9(1) \\
4.6(2) \\
28.1(1)\end{array}$ & $\begin{array}{l}\mathrm{p}<0.025 \\
\mathrm{p} \simeq 0.10 \\
\mathrm{p}<0.001\end{array}$ \\
\hline \multicolumn{6}{|c|}{ Small opacities: $\quad \log \frac{P}{1-P}=-7.27+0.0035$ (cum exp) +0.084 (age) $+\begin{array}{l}\{0.82 \text { if ex-smoker } \\
\{1.72 \text { if current smoker }\end{array}$} \\
\hline \multicolumn{6}{|c|}{ Pleural thickening: $\log \frac{P}{1-P}=-5.62+0.0024\left(\right.$ cum exp) +0.088 (age) $+\left\{\begin{array}{c}-0.41 \text { if ex-smoker } \\
\{0.42 \text { if current smoker }\end{array}\right.$} \\
\hline
\end{tabular}




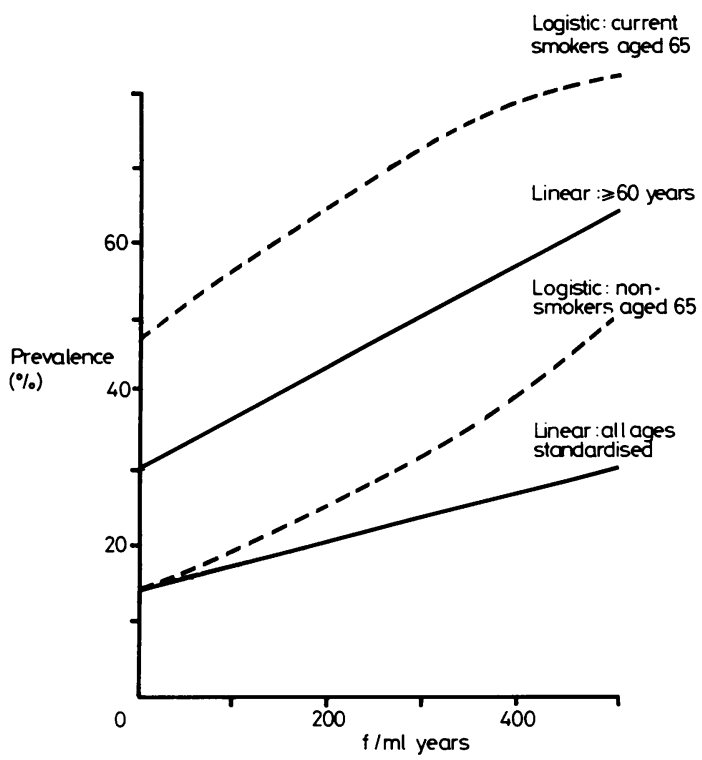

Prevalence of small opacities $(\geqslant 1 / 0)$ and cumulative exposure ( $\mathrm{f} / \mathrm{ml}$ years).

$\left(\chi^{2}(\mathrm{ldf})=5 \cdot 4, \mathrm{p} \simeq 0.02\right)$. The corresponding trend for prevalence of pleural thickening of the chest wall is less strong $\left(\chi^{2}(\mathrm{ldf})=2 \cdot 6, \mathrm{p} \simeq 0 \cdot 10\right)$.

Table 3 gives the prevalence of abnormalities by cumulative exposure for men aged 60 and over. Here, too, there is an association of small opacities with exposure $\left(\chi^{2}(\mathrm{ldf})=6.4, p \simeq 0.01\right)$ and a weaker one for pleural change $\left(\chi^{2}\right.$ (ldf $\left.)=0.9, p>0.20\right)$.

Results of the logistic regression analyses of abnormalities (table 4) show the independent effects of each of the three factors examined (cumulative exposure, age, and smoking), after allowing for the other two. Clear effects of cumulative exposure and age on the prevalence of small opacities are apparent and there is also some indication of a smoking effect $(p \simeq 0.02)$. The prevalence of pleural thickening on the chest wall is affected by age and more weakly by cumulative exposure $(p \simeq 0.02)$. There is no consistent evidence of a smoking effect. The data are insufficient to determine whether there are interactions between the factors.

The estimated exposure response relations for small opacities are graphed in the figure. The graph shows the linear relations computed from tables 2 and 3 , and that predicted from the logistic regression equation for age 65 . The latter includes two curves, one for current smokers and one for non-smokers. The curve for ex-smokers would be intermediate. For all these relations, standard errors of slopes and intercepts are large.
Among the 43 ex-employees for whom an earlier $x$ ray film had been obtained, small opacities $(\geqslant 1 / 0)$ were read in $18(42 \%)$ of the 1983 films and nine $(21 \%)$ of the films taken on average 8.9 years earlier. This difference derived from 10 men whose readings had deteriorated and two whose readings had improved. In the 24 pairs from unexposed men on average seven to eight years apart, no abnormality was read in the earlier film and one only in the later film. Since there was virtually no change in the cumulative exposure of the 43 ex-employees between their two $x$ ray films, the substantial increase in prevalence was presumably due in part to aging and in part to differences in radiographic technique.

\section{Discussion}

The usual criticism levelled at cross sectional morbidity studies in working groups is that selection may have removed a disproportionate number of employees who had suffered the ill effects of occupational exposure. It would be equally wrong to study only ex-employees. We tried in this survey to achieve a balance by including both present and past employees and analysing their joint experience. In addition to the logistic regression analysis presented in table 4 another analysis was made in which a fourth variable for ex or current employment was included. This showed that, having allowed for the other three factors, rates of change were higher in past than present employees but, statistically, not significantly so. The coefficient for the relation to exposure was, in fact, the same whether or not the fourth variable was included. We believe, therefore, that it is reasonable to base our estimate of exposure response on the experience of the combined sample. Even so, the relations illustrated in the figure entail great uncertainty, for which there are several reasons. Firstly, the exposure estimates, especially for the important period before about 1972, were approximate. Secondly, radiographic techniques and radiograph readings are major sources of variation. Thirdly, age, smoking, and probably other environmental factors all contribute to radiographic change. Finally, the study sample was quite small. In the absence of other information our data provide the only indication of risk in relation to exposure. Of the four lines shown in the figure, the two based on logistic regression and the one for men aged 60 or more are roughly parallel, and probably more valid than that based on age standardisation. These three lines suggest that by retirement age the increase in prevalence of small parenchymal opacities $(\geqslant 1 / 10)$ lies between $5 \%$ and $10 \%$ per $100 \mathrm{f} / \mathrm{ml}$ years. At present exposure levels in the Libby operation, reported by the company to average 
$0 \cdot 1 \mathrm{f} / \mathrm{ml}$, no excess of radiological change should be detectable after a working life of 40 years. The imprecision associated with radiological technique and reading error would be far greater than the expected level of risk.

There are few other data sets against which these findings may be compared. Our original studies of Quebec chrysolite miners ${ }^{6}$ gave a slope of about $0.6 \%$ per 100 fibre years and a later analysis, ${ }^{7}$ confined to men aged 60-69 with an average gross service of $42 \cdot 3$ years, gave a lower estimate $(0 \cdot 2 \%)$. Both these estimates were based on men still at work and it was concluded that the true gradients were probably steeper. A more recent study of the Quebec workers (JC McDonald et al, paper presented at XXI international congress on occupational help, Dublin, 1984) was based on current and past employees, used $x$ ray films taken with a similar technique to that at Libby, and one of the three readers took part in both studies. That study gave a slope of $4 \%$ per 100 fibre years, about half that in the present survey.

The radiographic study by NIOSH was based on the most recent chest $x$ ray films (188 in all) available in the local hospital for men employed five or more years and at some time since $1974 .{ }^{2}$ These men were all current employees at the time of the $x$ ray examination, were somewhat younger than those in our sample, but had been employed nearly four years longer and at a slightly higher average level of exposure. Despite this, and the fact that one of the readers was common to both studies, the prevalence rates of both parenchymal and pleural changes were substantially higher in our study than theirs. The slope of the logistic regression line for small opacities $(\geqslant 1 / 0)$ and cumulative exposure was also somewhat steeper in our data. We believe that these differences were due to better film quality and perhaps to the inclusion of ex-employees in our survey. This underlines the problems and imprecision of radiographic estimates of exposure response in dust exposed workers.

This research was supported by a grant to McGill University from WR Grace and Co. The chest $x$ ray films were taken at St John's Lutheran Hospital, Libby, Montana, under the supervision of Dr T Gill and read by $\operatorname{Dr} \mathbf{J}$ Gilson, Dr $\mathbf{R}$ Jones, and $\operatorname{Dr} G$ Sheers. The active participation of past and present employees and the company is gratefully acknowledged.

\section{References}

${ }^{1}$ McDonald JC, McDonald AD, Armstrong B, Sébastien P. Cohort study of mortality of vermiculite miners exposed to tremolite. Br J Ind Med 1986;43:436-44.

${ }^{2}$ Amandus HE, Wheeler R. Morbidity and mortality of vermiculite miners and millers exposed to tremolite-actinolite. Part II: Mortality. Am J Ind Med (in press).

${ }^{3}$ Dement JM, Zumwalde RD, Gamble JF, et al. Occupational exposure to talc containing asbestos. Washington, DC: US Government Printing Office, 1980. (National Institute for Occupational Safety and Health technical report.)

${ }^{4}$ International Labour Office. Guidelines for the use of ILO international classification of radiographs of pneumoconioses. Geneva: ILO, 1980. (Occupational Safety and Health series 22 Rev 80.)

${ }^{5}$ Baker RJ, Nelder JA. The GLIM System: release 3. Oxford: Numerical Algorithm Group, 1978.

${ }^{6}$ Rossiter CE, Bristol LJ, Cartier PH, et al. Radiographic changes in chrysotile mine and mill workers of Quebec. Arch Environ Health 1972;24:388-400.

${ }^{7}$ Liddell FDK, Gibbs GW, McDonald JC. Radiological changes and fibre exposure in chrysotile workers aged 60-69 years at Thetford Mines. Ann Occup Hyg 1982;26:889-98. 